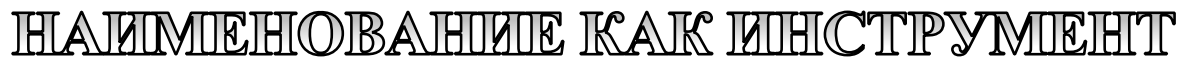

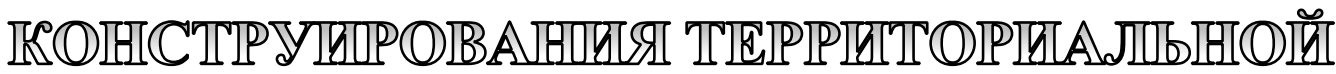

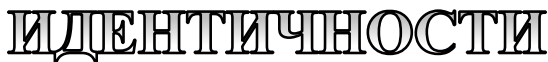

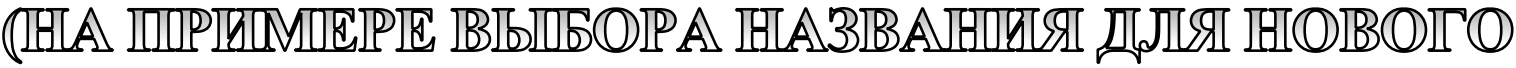

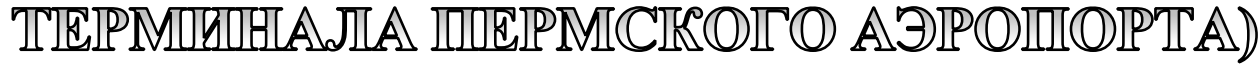

М.В. Назукина, Пермский федеральный исследовательский центр УрО РАН; Пермский государственный национальный исследовательский университет

Рассматриваются особенности практик наименования (нейминга) как аспекта территориальной идентичности. Дана характеристика наименований как инструмента политики идентичности. Определено, что нейминг является важным способом конструирования и поддержания идентичности. Выделены две основные функциональные роли наименования. Первый конструирование новых традиций или воссоздание старых. Второй репрезентация сообщества, фоомирование через наделение имени образа вовне. Дается характеристика данного инструмента политики идентичности на примере изучения Конкурса на выбор названия терминала пермского аэропорта, который прошел в октябре-ноябре 2017 года. Выбор объекта исследования обусловлен символической ролью аэропорта («лицо», «ворота» в город), поэтому он может характеризовать состояние территориальной идентичности. Анализ конкурса показал конкуренцию географических (Пермь, Большое Савино) и личностных названий (имени С.П. Дягилева, имени П.А. Соловьева, имени А.Г. Солдатова, имени С.А. Белова, имени И.И. Любимова, «Строганов»). Определено, что дискурсивные стратегии презентации номинантов были связаны с достижениями людей, их вкладом в развитие места. Дана оценка Конкурса в контексте специфики пермской региональной идентичности. Доказывается, что выбор прежнего названия «Большое Савино» демонстрирует пермский традиционализм, тягу к привычному в противовес изменениям.

Ключевые слова: территориальная идентичность, политика идентичности, наименование, онимь, конкурс, аэропорт, Пермь.

\section{Введение}

В начале октября 2018 года министр культуры РФ Владимир Мединский предложил переименовать многие аэропорты в городах страны, включая Пермь и Екатеринбург. По его мнению, никто не может запомнить их названия, поэтому он 54 предложил свой вариант названия одного из аэропортов в честь историка Василия Татищева, который считается основателем Перми и Екатеринбурга. Инициировав проект «Великие имена России», в рамках которого 45 российских аэропортов будут названы в честь выдающих- 
ся соотечественников ${ }^{1}$, он вновь актуализировал проблему переименования значимых объектов социальной инфраструктуры в этих городах.

В Екатеринбурге, к примеру, в социальных сетях запустили голосование с предложениями, в честь кого стоило бы переименовать аэропорт [10]. В пермском случае парадоксальность ситуации заключается в том, что год назад в 2017 году конкурс по выбору названия уже был проведен: «Мы буквально в прошлом году использовали практику обращения к жителям для выбора названия новому аэровокзальному комплексу, проводили консультации с экспертами, пермяки голосовали через портал «Управляем вместе», через СМИ и соцсети. На голосование тогда были предложены в том числе и имена наших известных земляков: Соловьев, Дягилев. Но в итоге из более чем 12 тысяч голосов, $44 \%$ пермяки отдали за традиционное название «Большое Савино». Проведенная нами социология этот выбор подтвердила. Оно уже почти год встречает и провожает наших жителей и гостей края в новом аэропорту», - прокомментировал инициативу губернатор М.Г. Решетников [8].

\section{Наименование как инструмент политики идентичности}

В структуре территориальной идентичности одними из наиболее значимых семиотических средств номинации компонентов феномена являются онимы (т.е. названия), которые тесным образом связаны с культурой и историей территориального сообщества. Наделение объектов инфраструктуры (коммерческих и социальных предприятий, например, магазинов, ресторанов и пр.) наименованиями (нейминг как инструмент), связанными с той или иной местной, региональной, этнической, конфессиональной и т.д. спецификой, позволяют судить о низовом уровне интереса местных жителей к территориальной идентифи- кации, а значит, могут рассматриваться в качестве маркера интенсивности и стратегической нацеленности в идентификации тех или иных территориальных образований со стороны местных властей и сообщества в целом.

Таким образом, указанный инструмент (наделение именем или нейминг) является важным способом конструирования и поддержания идентичности. В имени (топониме или ониме) находит отражение идентичность сообщества (национальная, этническая, территориальная и пр.), поэтому вопросы переименования всегда вызывают бурные обсуждения и часто приводят к конфликтам.

В исследовательской литературе подчеркивается связь переименования с политическими практиками. Дерек Алдерман отмечает, что нейминг - это мощный инструмент для продвижения идентификации с прошлым и нахождения себя в более широких сетях памяти [1, с. 195]. Кроме того, наименование объектов, также как и названия улиц, обеспечивают пересечение идеологических структур с пространственными практиками повседневной жизни [2, с. 311].

Наделение названием или его смена, таким образом, является одним из инструментов политики идентичности, под которой понимается «совокупность ценностных ориентиров, практик и инструментов формирования и поддержания национальной (национально-государственной) гражданской и иных форм макрополитической идентичности» [20, с. 165]. Политика идентичности проводится элитными группами, интеллектуалами, самим сообществом. Так, властью создаются мифы, ритуалы и культы, значимые праздничные события, культивируются «культурные герои» и прочее.

Характеристика наименования как инструмента политики идентичности связана с возможностью с помощью него кон-

\footnotetext{
${ }^{1}$ Решение, в честь кого назвать аэропорт, будет приниматься по итогам общенационального голосования на специальном сайте «Великие имена». URL: https://xn--80adjaaqabpiqn.xn--p1ai/about (дата обращения: 08.10.2018).
} 
струировать традиции или воссоздавать старые. Так происходило, например, в 1990-е годы в России, когда прошла волна переименования городов и улиц, связанная с отказом от советского наследия. Кроме того, с помощью названий формируются метки сообщества, которые определяют его образ вовне.

Функция репрезентации тесно связана с маркетинговым подходом позиционирования наименований. Не случайно в маркетинге нейминг (naming) определяется комплекс работ, направленный на создание успешных маркетинговых имен для торговых марок и статусных названий компаний [13]. Нейминг рассматривается как подчиненный целям и задачам брендинга, позиционирования марки товара. Названия, следовательно, позиционируют не только объект, но и место, территорию его производства или нахождения.

\section{Конкурс на выбор названия терминала пермского аэропорта}

В последние годы в Пермском крае было три громких инициативы выбора имени объекту, имеющему символическую значимость для регионального сообщества. Первая - это голосование, инициированное БК «Парма» за смену названия клуба (2016). Во время одного из матчей было предложено ответить на вопрос, какое название для клуба лучше: «Парма» или «Урал-Грейт» [4]. Вторая решение конкурсной комиссии по выбору названия для футбольного манежа в пользу названия «Пермь Великая» (2016) [17]. И третье, самое значимое, - вопрос о выборе названия для нового терминала пермского аэропорта (2017).

Последнее событие имело самый высокий общественный резонанс. Нами проанализирована данная конкурсная практика, как стимулировавшая дискуссии о пермской идентичности, которая показала не только значимые символические атрибуты, но и общий вектор конструирования региональной идентичности в крае. В этом контексте его можно считать по- казательным относительно отличительных символических атрибутов и характеристик пермского сообщества.

\section{Ход конкурса}

Пермский аэропорт «Большое Савино» был открыт в 1965 году. Название тогда было выбрано по географическому принципу, поскольку аэропорт разместился в д. Большое Савино рядом с Пермью [19].

Вопрос о переименовании пермского аэропорта рассматривался в контексте культурных инноваций в период губернаторства О.А. Чиркунова. В 2011 году министр культуры Николай Новичков предложил сменить название «Большое Савино» на «Международный аэропорт «Сергей Дягилев». Однако тогда инициатива министра продолжения не имела. ФГУП «Пермские авиалинии» тогда разъяснило, что «название «Большое Савино» внесено во все справочники, включая зарубежные, с присвоением соответствующих международных кодов. И переименование не только займет много времени, но и потребует серьезных бюджетных вливаний» [7].

В 2000-е годы потребовались масштабная реконструкция и строительство нового здания аэропорта, что завершилось открытием в 2017 году. Новый губернатор М.Г. Решетников инициировал выбор названия для построенного терминала. «На имя губернатора Пермского края неоднократно поступали предложения присвоить новому терминалу имя выдающихся деятелей, прославивших Пермский край. С другой стороны, как отмечают эксперты, достаточно много сторонников, выступающих за сохранение существующего статус-кво. Задача экспертной комиссии - аккумулировать мнения и путем рейтингового голосования принять решение», - так презентовал Конкурс портал «Управляем вместе» [22].

Для определения вариантов названия терминала была создана экспертная группа из известных пермяков (Надежда 
АВТОРИТЕТНОЕ МНЕНИЕ

Беляева, президент Пермской государственной художественной галереи, член Общественной палаты Пермского края; Александр Иноземцев, управляющий директор - генеральный конструктор АО «ОДК-Авиадвигатель»; Светлана Федотова, историк, журналист, писатель, автор книг о Пермском крае; Александр Башминов, генеральный директор баскетбольного клуба «Парма», член Общественной палаты Пермского края; Теодор Курентзис, художественный руководитель Пермского театра оперы и балета и другие) [23]. Экспертная группа предложила восемь вариантов возможного названия нового терминала пермского аэропорта: имени С.П. Дягилева, имени П.А. Соловьева, имени А.Г. Солдатова, имени С.А. Белова, имени И.И. Любимова, «Строганов», Пермь, Большое Савино. Кроме того, можно было предложить свой вариант. Голосование происходило на сайте «Управляем вместе» в период с 19 октября по 20 ноября 2017 года. В нем приняло участие более 12 тыс. жителей Пермского края, всего получено 12442 голоса. Итоги голосования объявили ко дню рождения Пермского края (табл. 1).

Анализируя состав номинантов, можно сделать вывод о том, что большинство предложенных названий были персонифицированными и связанными с выдающимися пермяками. Это, как представляется, отражает распространенную практику называть аэропорты в честь людей ${ }^{2}$. Два предложенных варианта («Пермь» и «Большое Савино») были географическими. Дискурсивные стратегии презентации номинантов на сайте связаны с достижениями, продвижением территории, вкладом в развитие места (табл. 2).
Итоги голосования на выбор названия

Таблииа 1 нового терминала пермского аэропорта [22]

\begin{tabular}{|c|c|}
\hline Вариант названия & Голоса (чел.) \\
\hline $\begin{array}{c}\text { Терминал имени } \\
\text { С.П. Дягилева }\end{array}$ & 925 \\
\hline $\begin{array}{c}\text { Терминал имени } \\
\text { П.А. Соловьева }\end{array}$ & 3208 \\
\hline $\begin{array}{c}\text { Терминал имени } \\
\text { А.Г. Солдатова }\end{array}$ & 225 \\
\hline $\begin{array}{c}\text { Терминал имени } \\
\text { С.А. Белова }\end{array}$ & 66 \\
\hline $\begin{array}{c}\text { Терминал имени } \\
\text { И.И. Любимова }\end{array}$ & 701 \\
\hline Терминал «Строганов» & 1150 \\
\hline Терминал Пермь & 5434 \\
\hline Терминал Большое Савино & 657 \\
\hline $\begin{array}{c}\text { или предложите свое } \\
\text { название терминала }\end{array}$ & \\
\hline
\end{tabular}

Лоббирование варианта

«Терминал имени П.А. Соловьева»

Из всех претендентов на название нового терминала аэропорта активнее всего шло лоббирование имени авиаконструктора Павла Соловьева. Из экспертов его поддерживала известная пермская писательница Светлана Федотова. По ее мнению, присвоение новому терминалу аэропорта имени Павла Соловьёва - это и важный символический шаг, и дань исторической справедливости: «Главное достижение Соловьёва - создание двухконтурного реактивного двигателя. Пермский авиаконструктор опередил время, с него началась эра реактивного двигателестроения»; «Нет ему равных по значимости фигуры. Недаром британская газета «Гардиан» некролог о нём начала словами «Последний из великих». Пермский авиаконструктор стоит в одном ряду с такими великими людьми, как Галилео Галилей, Леонардо да Винчи, Микеланджело» [6].

\footnotetext{
${ }^{2}$ По Данным Викепедии, в мире 208 аэропортов, названных в честь людей. URL: https://ru.wikipedia.org/wiki/\%D0\%9A\%D0\%B0\%D1\%82\%D0\%B5\%D0\%B3\%D0\%BE\%D1\%80\%D0\%B8 \%D1\%8F:\%D0\%90\%D1\%8D\%D1\%80\%D0\%BE\%D0\%BF\%D0\%BE\%D1\%80\%D1\%82\%D1\%8B,_\%D0\% BD\%D0\%B0\%D0\%B7\%D0\%B2\%D0\%B0\%D0\%BD\%D0\%BD\%D1\%8B\%D0\%B5_\%D0\%B2_\%D1\%87\% $\mathrm{D} 0 \% \mathrm{~B} 5 \% \mathrm{D} 1 \% 81 \% \mathrm{D} 1 \% 82 \% \mathrm{D} 1 \% 8 \mathrm{C} \_\% \mathrm{D} 0 \% \mathrm{BB} \% \mathrm{D} 1 \% 8 \mathrm{E} \% \mathrm{D} 0 \% \mathrm{~B} 4 \% \mathrm{D} 0 \% \mathrm{~B} 5 \% \mathrm{D} 0 \% \mathrm{~B} 9$ (дата обращения: 15.07.2018).

${ }^{3}$ Интересно, что юморист Максим Галкин во время гастролей в Перми в шутку предложил ещё два варианта названия аэропорта. Он считает, что честно было бы назвать терминал «Долгострой», но для того, чтобы в будущем с аэровокзалом не было проблем, можно дать ему имя «Путин» [16].
} 
Ключевая презентация номинированных названий ${ }^{4}$

\begin{tabular}{|c|l|}
\hline Вариант названия & \multicolumn{1}{c|}{ Презентация номинантов } \\
\hline $\begin{array}{c}\text { Терминал имени } \\
\text { С.П. Дягилева }\end{array}$ & $\begin{array}{l}\text { С.П. Дягилев - русский театральный и художественный деятель, антрепренёр, } \\
\text { искусствовед, пропагандист русского искусства за рубежом. }\end{array}$ \\
\hline $\begin{array}{c}\text { Терминал имени } \\
\text { П.А. Соловьева }\end{array}$ & $\begin{array}{l}\text { П.А. Соловьев - советский и российский конструктор авиационных двигателей, } \\
\text { основоположник газотурбинного двигателестроения в СССР. }\end{array}$ \\
\hline $\begin{array}{c}\text { Терминал имени } \\
\text { А.Г. Солдатова }\end{array}$ & $\begin{array}{l}\text { А.Г. Солдатов - деятель советской оборонной промышленности; лауреат Сталинской } \\
\text { премии (1949). }\end{array}$ \\
\hline $\begin{array}{c}\text { Терминал имени } \\
\text { С.А. Белова }\end{array}$ & $\begin{array}{l}\text { С.А. Белов - Олимпийский чемпион 1972 года, двукратный чемпион мира (1967, 1974), } \\
\text { четырехкратный чемпион Европы (1967, 1969, 1971, 1979), двукратный обладатель } \\
\text { Кубка Европейских чемпионов (1969, 1971), чемпион Универсиады 1970 года. }\end{array}$ \\
\hline $\begin{array}{c}\text { Терминал имени } \\
\text { И.И. Любимова }\end{array}$ & $\begin{array}{l}\text { И.И. Любимов - российский предприниматель (купец 1-й гильдии, представитель } \\
\text { династии Любимовых), меценат и общественный деятель, городской голова Перми в } \\
\text { 1871-1874 и 1876-1878 гг. Потомственный почётный гражданин }\end{array}$ \\
\hline $\begin{array}{c}\text { Терминал } \\
\text { «Строганов» }\end{array}$ & $\begin{array}{l}\text { С именем Строгановых связано создание экономической мощи Прикамья, развитие } \\
\text { здесь культуры, искусства, меценатства, социальной сферы. }\end{array}$ \\
\hline Терминал «Пермь» & $\begin{array}{l}\text { Пермь - крупный многоотраслевой промышленный, научный, культурный и } \\
\text { логистический центр Урала. }\end{array}$ \\
\hline $\begin{array}{c}\text { Терминал } \\
\text { Аэропорт название получил от деревни Большое Савино, на территории которой } \\
\text { расположен. }\end{array}$ \\
\hline «Большое Савино»
\end{tabular}

АО «ОДК-Авиадвигатель» также активно продвигал данную персону. Аргументы сводились к следующему: «напрямую связан с авиацией и самолетами»; «дань памяти в честь 100-летнего юбилея выдающегося конструктора» [14]. «Имя мирового масштаба. Конструктор. Создал школу, которая процветает» [5].

Продвижение шло и через стимулирование к участию в голосовании работников АО «ОДК-Авиадвигатель». В социальных сетях отмечалось, что «сотрудников пермского завода АО «Авиадвигатель» в принудительном порядке заставляют голосовать в опросе по выбору наименования нового терминала пермского аэропорта за вариант «Терминал имени П.А. Соловьева»... официальное письмо и начальники отделов собирают списки» [24].

На сайте Пермского политехнического университета также было размещено обращение в поддержку авиаконструктора Павла Соловьева: «Павел Александрович Соловьев был заведующим кафедрой «Авиационные двигатели» в ПНИПУ. Более 30 лет он возглавлял Пермское конструкторское бюро (ныне АО «ОДКАвиадвигатель»). Именно в Перми под его руководством созданы авиационные двигатели, позволившие выйти России на мировой уровень в авиации. Более $40 \%$ всех авиаперевозок в СССР обеспечивали двигатели конструкции П.А. Соловьева... Наш город вправе гордиться тем, что здесь жил и работал П.А. Соловьев!» [9].

Такая активность и мобилизация, безусловно, может объяснить резкий рост количества голосов у этого варианта, который оказался на втором месте.

\section{Культурная идентичность - имя Дягилева}

Второй претендент, часто всплывавший в обсуждениях, которого поддержали многие эксперты, - это «терминал имени С.П. Дягилева», название больше ориентированное на внешний имидж города как «культурной столицы». Не случайно его поддерживал художественный руководитель Пермского театра оперы и балета Теодор Курентзис. Эксперты подчеркивали связь с идентичностью и культурным имиджем города. «И здесь подойдет международное имя - «Сергей Дягилев». Сейчас стратегия города более культурная, Пермь известна театральными активностя-

\footnotetext{
${ }^{4}$ Составлено по: [22]. 
ми. Я пару раз летала в Пермь, самолет наполнен англоязычными людьми, которые как раз знают импресарио и направляются на подобные мероприятия», - отмечала, к примеру, Наталья Рыбальченко, основатель компании «POINT.TOЧКА РАЗВИТИЯ» [21].

Эксперт по брендингу городов, руководитель московской компании CityBranding Василий Дубейковский также заметил, что имя Дягилева отражает идентичность места: «Если, конечно, основная задача - чтобы человек столкнулся с культурным кодом, то название должно коррелировать со славой Перми и Пермского края. Здесь мне сразу приходят на ум названия «Дягилев» или даже «Посикунчик». Главное то, что отличает Пермь от всех городов мира» [21].

Кроме того, имя Дягилева рассматривалось выгодным и с маркетинговой точки зрения. Советник по вопросам туризма министра культуры РФ Николай Новичков назвал прошедший конкурс примером нейминга без дальнейшего продвижения, когда «пермяки предпочли привычное название «Большое Савино», а не уникальные для Прикамья символические имена» [18]. «Я буду всю жизнь припоминать пермякам выбор для нового аэропорта названия «Большое Савино» и корить их», заявил экс-министр. «Это словосочетание не вызывает никакого желания прилететь в Пермь. Это не отрицательный бренд, а нулевой, плоский и не развивающийся. Он никак не идентифицирует Пермский край» [3], - объяснил он.

\section{Итоги конкурса и выводы}

Несмотря на продвижение некоторых названий, победу в конкурсе одержало старое имя «Большое Савино». Анализи- руя дискурс СМИ, посвященный новости об итогах конкурса, можно прийти к выводу, что ставка была сделана на привычность: «Пермяки решили назвать новый аэропорт по-старому», ««Большое Савино» привычнее»; «Пермяки решили не пробовать что-то новенькое» 5 . Стоит отметить, что параллельно голосование проходило на других порталах, в частности, на 59.ru: «Новый терминал пермского аэропорта может сохранить старое название - Большое Савино, а может стать Дягилевым, Любимовым, Павлом Соловьевым, Анатолием Солдатовым, Сергеем Беловым или просто Пермью. Какой вариант больше нравится вам?». Показательно, что и здесь большинство (71\%) проголосовал за Большое Савино [15].

Таким образом, если оценивать состоявшийся конкурс в контексте специфики пермской региональной идентичности, то можно сделать вывод, что возобладал пермский традиционализм. Пермский региональный менталитет, для которого характерна тяга к привычному, типичному, устоявшемуся, не очень охотно принимает новации и изменения [12]. Характерный дискурс здесь выстраивается вокруг следующего рассуждения: «если имя должно быть связано с идентичностью региона, пусть оно останется прежним, поскольку оно уже нам „привычно“»».

Сам конкурс показал инструментальные возможности управления продвижением кандидата на имя (терминал им. Соловьёва). Похожая практика наблюдалась в 2009 году, когда пермяки выбирали «Имя Перми Великой»: предприятия машиностроительного комплекса активно поддержали кандидатуру А.Г. Солдатова, «Уралсвязьинформ» лоббировал фигуру А. Попова, а «Мотови-

\footnotetext{
${ }^{5}$ См., например, характерные оценки: Стало известно, как пермяки назвали новый терминал аэропорта // Сетевое издание WWW.PROGOROD59.RU, 21.11.2017. URL: https://progorod59.ru/news/18670 (дата обращения: 15.07.2018); Пермяки решили назвать новый аэропорт по-старому // Сетевое издание NewsPerm.ru, 21.11.2017. URL: https://www.permnews.ru/novosti/society/2017/11/21/permyaki_reshili_nazvat_novyy_aeroport_po-staromu/ (дата обращения: 15.07.2018); Жигулёвский Г. «Большое Савино» привычнее. Пермяки выбрали название для нового терминала аэропорта // Звезда, 21.11.2017. URL: http://zvzda.ru/news/109961c33285 (дата обращения: 15.07.2018)
} 
лихинские заводы» - Н. Славянова [11].

Однако, если конкурс «Имя Перми Великой» поднял важный вопрос о критерии выбора ключевого символа - имени региона и выбор символа Имени был связан внутренним дискурсом, самоопределением человека как пермяка, то конкурс выбора названия для нового терминала аэропорта должен был сработать, прежде всего, во вне - как внешняя метка пермской уникальности. Для пермского же сообщества эта «метка» оказалась связана укоренившимся названием.

\section{Библиографический список}

1. Alderman D. Place, naming and the interpretation of cultural landscapes // in: The Ashgate research companion to heritage and identity / ed. by B. Graham, P. Howard, P. 195-213.

2. Azaryahu $M$. The power of commemorative street names // Environment and planning D Society and Space. - 1996. - Vol. 14(3). - P. 311-330.

3. «Всю жизнь буду корить пермяков за название «Большое Савино», - Николай Новичков // Бизнес класc, 26.08.2018. URL: https://www.business-class.su/news/2018/08/26/vsyu-zhizn-budu-koritpermyakov-za-nazvanie-bolshoe-savino-nikolai-novichkov (дата обращения: 15.10.2018).

4. «Парма» проведет голосование за выбор нового названия команды Basketball.ru, 30.08.2016. URL: http://www.basketball.ru/news/main/main 42458.html (дата обращения: 15.07.2018).

5. Александр Иноземцев - гость студий РБК-Пермь. Итоги, 01.11.2017 Новости ПГНИПУ. URL: http://pstu.ru/intresting/2017/11/03/7581/ (дата обращения: 15.07.2018).

6. Аэропорт «Павел Соловьев». В Перми продолжают выбирать имя для терминала // Аргументы и факты. - № 44. - 01.11.2017. URL: http://www.perm.aif.ru/gorod/details/aeroport_pavel_solovev_v_permi_prodolzhayut_vybirat_imya_dlya_terminala (дата обращения: 15.07.2018).

7. Барков Д. Пермский креатив: терминал аэропорта получит имя // «ФедералПресс», 11.10.2017. URL: http://fedpress.ru/article/1872644 (дата обращения: 15.07.2018).

8. В Прикамье не будет проводиться новое голосование по выбору названия аэропорта. Коммерсант, 11.10.2018. URL: https://www.kommersant.ru/doc/3766667 (дата обращения: 08.10.2018).

9. Выбираем имя для нового терминала аэропорта // Новости ПГНИПУ. 17.11.17. URL: http://pstu.ru/intresting/2017/11/03/7581/ (дата обращения: 15.07.2018).

10. Мединский предложил переименовать аэропорт Кольцово - реакция уральцев // АиФ, 05.10.2018. URL: http://www.ural.aif.ru/society/medinskiy_predlozhil_pereimenovat_aeroport_kolcovo_reakciya_uralcev?utm_source=yxnews\&utm_medium=desktop (дата обращения: 08.10.2018).

11. Назукина М.В. Конкурс «Имя Перми Великой» как зеркало пермской идентичности // Бюллетень пермской социологии. - Пермь, 2010. - С. 133-139.

12. Назукина M.B. Между Уралом и Поволжьем: поиски пермской идентичности. Пермь: «Печатный салон «Гармония», 2018. 196 с.

13. Нейминг. URL: http://xn--cladjdpde.name/naming/nejming.html (дата обращения: 15.07.2018).

14. Овчинников C. «Авиадвигатель» с названием аэропорта определился. Имя Соловьева в качестве названия для аэропорта - в нашем сюжете. URL: http://t7-inform.ru/s/videonews/20171102104815 (дата обращения: 15.07.2018).

15. Опросы 59.ru. URL: https://59.ru/poll/stat/355502819430400.html (дата обращения: 15.07.2018).

16. Пародист Максим Галкин предложил два названия для нового аэропорта // АиФ Пермь, 28.10.2017. URL: http://www.perm.aif.ru/society/details/parodist_maksim_galkin_predlozhil_dva_nazvaniya_dlya_novogo_aeroporta (дата обращения: 15.07.2018).

17. Пермский манеж будет называться «Пермь Великая» // Спорт-Экспресс, 24.03.2016. URL: https://www.sport-express.ru/football/rfpl/news/980938/ (дата обращения: 15.07.2018).

18. Пермь ассоциируется у туристов с «Уральскими пельменями» // РБК, 15.06.2018. URL: https://perm.rbc.ru/perm/freenews/5b2399e49a7947ab8f419676 (дата обращения: 15.07.2018).

19. Под открытым небом: история аэропорта «Большое Савино» // Онлайн-музей истории Савинского поселения. URL: http://museum.savinoclub.ru/bolshoe-savino/ (дата обращения: 15.07.2018).

20. Политическая идентичность и политика идентичности: в 2 т. Т. 1: Идентичность как категория политической науки: словарь терминов и понятий / отв. ред. И.С. Семененко. - М.: РОССПЭН, 2011. -208 c.

21. Посикунчик или Дягилев: пермяки предлагают названия для нового терминала // РБК, 12.10.2017. URL: https://perm.rbc.ru/perm/freenews/59df65f89a7947cb5ed1277d (дата обращения: 15.07.2018).

22. Проект «Управляем вместе». URL: http:/www.permkrai.ru/program/votings?group_id=1 (дата обращения: 15.07.2018). 
23. Состав экспертной Комиссии по вопросу присвоения наименования терминалу аэропорта г. Перми // Сайт губернатора и Правительства края. URL: http://www.permkrai.ru/program/data/voting/commission.pdf (дата обращения: 15.07.2018).

24. Сотрудников пермского завода заставляют голосовать в опросе по выбору названия новому аэропорту Перми // Vikiperm, 31.10.2017. URL: https://vikiperm.com/news/1349-sotrudnikovpermskogo-zavoda-zastavlyayut-golosovat-v-oprose-po-vyboru-nazvaniya-novomu-aeroportu-permi/ (дата обращения: 15.07.2018).

\title{
NAMING AS A TOOL OF CONSTRUCTING TERRITORIAL IDENTITY (ON THE EXAMPLE OF CHOOSING THE NAME FOR THE NEW TERMINAL OF THE PERM AIRPORT)
}

\author{
M.V. Nazukina \\ Perm Federal Research Center UB RAS \\ Perm State National Research University
}

The article observes the peculiarities of naming practices as an aspect of territorial identity. The characteristic of names as a tool of identity politics is given. It is determined that naming is an important way of constructing and maintaining the identity. Two main functional roles of naming are singled out. The first is the construction of new traditions or the reconstruction of the old ones. The second is the representation of the community, the formation through giving the name of the image outside. The characteristic of this tool of identity policy is given on the example of studying the Contest for the choice of the name of the terminal of the Perm airport, which was held in OctoberNovember 2017. The choice of the object of the study is due to the symbolic role of the airport («face», «gates» to the city), so it can characterize the state of territorial identity. The analysis of the Contest showed the competition of geographical (Perm, Bolshoye Savino) and personal names (named after S.P. Diaghilev, P.A. Solovyov, A.G. Soldatov, S.A. Belov, I.I. Lyubimov, «Stroganov»). It was determined that the discourse strategies of the presentation of the nominees were linked to the achievements of people, their contribution to the development of the place. The evaluation of the Contest in the context of the specifics of the Perm regional identity is given. It is proved that the choice of the former name «Bolshoye Savino» demonstrates the Permian traditionalism and the craving for something familiar as opposed to changes.

Keywords: territorial identity, identity politics, naming, names, Contest, airport, Perm.

\section{Сведения об авторе}

Назукина Мария Викторовна, кандидат политических наук, научный сотрудник отдела по исследованию политических институтов и процессов, Пермский федеральный исследовательский центр УрО РАН (ПФИЦ УрО РАН), 614900, г. Пермь, ул. Ленина, 13А; доцент кафедры политических наук, Пермский государственный национальный исследовательский университет (ПГНИУ), 614990, Россия, г. Пермь, ул. Букирева, 15; e-mail: nazukina @ mail.ru 